\title{
EFFECT OF CHOLECYSTOKININ-OCTAPEPTIDE ON DOPAMINE RELEASE FROM SLICES OF CAT CAUDATE NUCLEUS ${ }^{1}$
}

\author{
R. MARKSTEIN*,2 AND T. HÖKFELT \\ * Preclinical Research, SANDOZ LTD., CH-4002 Basle, Switzerland, and $\ddagger$ Department of Histology, Karolinska Institutet, \\ Stockholm, Sweden
}

Received August 2, 1983; Accepted August 19, 1983

\begin{abstract}
The cat caudate nucleus has been reported to possess a rich and fairly even distribution of nerve endings, containing both dopamine- and cholecystokinin-like peptides. In this study, the effect of cholecystokinin-octapeptide (CCK-8) on basal and electrically evoked tritium outflow from slices of cat caudate nucleus previously labeled with $\left[{ }^{3} \mathrm{H}\right]$ dopamine was examined. Fvoked tritium outflow from slices of cat caudate nucleus was $\mathrm{Ca}^{2+}$ dependent and abolished by tetrodotoxin, suggesting that it reflects action potential-induced $\left[{ }^{3} \mathrm{H}\right]$ dopamine release. In the presence of bovine serum albumin and bacitracin, the sulfated but not the unsulfated form of CCK- 8 inhibited both basal and electrically evoked tritium outflow from slices of cat caudate nucleus at very low concentrations. CCK-8 sulfate was efficient in causing this effect in concentrations down to $10^{-14} \mathrm{M}$, and the maximum effect was obtained with $10^{-11} \mathrm{M}$. In contrast, without bovine serum albumin and bacitracin, no inhibitory effect of CCK-8 sulfate was seen, but instead, a marked enhancement of tritium outflow at $10^{-7} \mathrm{M}$ was observed. The findings suggest that CCK-8 sulfate in dopamine/CCK coexistence regions is involved in regulating dopamine release.
\end{abstract}

Peptides belonging to the cholecystokinin (CCK) family (Ivy and Oldberg, 1928; Jorpes and Mutt, 1973) are present in the mammalian central nervous system (Vanderhaeghen et al., 1975; Dockray, 1976, 1980; Rehfeld, 1977, 1978; Dockray et al., 1978; Robberbrecht et al., 1978; Beinfeld, 1981; Beinfeld et al., 1981). Recently it has been observed (Hökfelt et al., 1980a, b) that, in the ventral mesencephalon of the rat, some CCK-immunoreactive neurons are identical to dopamine neurons of the A8-A10 cell groups as originally defined by Dahlström and Fuxe (1964), suggesting neuronal coexistence of dopamine and a CCK-like peptide(s). Most of the dopamine/CCK-immunoreactive neurons are present in the ventral tegmental area, whereas the majority of the dopamine neurons in the zona compacta of the substantia nigra seem to lack the peptide. In agreement, CCK-like immunoreactivity seems to be present only in some of the dopamine nerve terminals, for example in parts of the nucleus accumbens and tuberculum olfactorium. In fact, retrograde tracing combined with immunohistochemistry have demonstrated directly a dopamine/CCK pathway from the ventral tegmental area to the medial

\footnotetext{
${ }^{1}$ This study was in part supported by the Swedish Medical Research Council (04X-2887). We wish to thank Ms. Elisabeth Stutz and Mrs. Elisabeth Björklund for their expert secretarial help.

${ }^{2}$ To whom correspondence should be addressed.
}

nucleus accumbens (Hökfelt et al., 1980b), whereas CCKlike immunoreactivity apparently was absent in the majority of the dopamine nerve fibers in the caudate nucleus of the rat (Hökfelt et al., 1980a, b).

Coexistence of a classical transmitter such as dopamine and a peptide occurs in many neuronal systems (Hökfelt et al., 1982) but, so far, the physiological significance of this phenomenon in the central nervous system is unclear (Hökfelt et al., 1982). Skirboll et al. (1981) have shown that sulfated CCK-7 and CCK-8 peptides increase the activity of dopamine cells in those areas that are rich in CCK/dopamine neurons. Biochemical studies have demonstrated effects on dopamine content in the striatum (Fekete et al., 1981) and on turnover of striatal dopamine (Fuxe et al., 1980; Kovacs et al., 1981) after intraventricular injections of CCK peptides.

Effects of CCK peptides on binding of dopamine agonists to striatal membrane preparations have also been demonstrated (Fuxe et al., 1981; Agnati et al., 1983). Furthermore, sulfated CCK-7 and CCK-8 enhance electrically induced dopamine release from the medial nucleus accumbens in vitro, whereas effects in the caudate nucleus are limited (R. Markstein, L. Skirboll, and T. Hökfelt, submitted for publication). It is, however, very difficult to assess to what extent, or if at all, these effects can be related to the coexistence phenomenon; among others, since non-CCK dopamine and non-dopamine 
CCK systems may project to the same areas as the dopamine/CCK neurons (see Meyer et al., 1982). Furthermore, the dopamine/CCK coexistence areas in the rat are very small (e.g., caudal, medial nucleus accumbens) and it is difficult to obtain sufficient amounts of tissue for biochemical experiments.

Recently, we have observed that in the cat virtually all mesencephalic dopamine neurons seem to contain a CCK-like peptide, including the dopamine neurons in the zona compacta of the substantia nigra ( $\mathrm{T}$. Hökfelt, T. Jacobs, L. Skirboll, G. Norell, A. Faden, G. Dockray, M. Goldstein, and M. Brownstein, manuscript in preparation). In agreement, dense overlapping networks of CCK-immunoreactive and dopamine fibers can be found in several limbic projection areas as well as in the caudate nucleus. These findings may provide an improved experimental situation to elucidate the interaction between the two compounds at a functional level. The size of the caudate nucleus in the cat as well as the homogeneous distribution of nerve endings containing both transmitter aspects provide a rich source of tissues for various types of biochemical experiments. In the present paper, we will describe the effect of CCK- 8 on the release of dopamine from slices of the cat caudate nucleus induced by electrical stimulation in vitro.

\section{Materials and Methods}

Drugs. The following chemicals were used in the present study: cholecystokinin-octapeptide, sulfated form (CCK-8s) (Universal Biologicals, Cambridge, UK); cholecystokinin-octapeptide, non-sulfated form (CCK-8) (Peninsula Laboratories, Belmont, $\mathrm{CA}$ ); bovine serum albumin (BSA) (RIA grade; Sigma Chemical Co., St. Louis, MO); bacitracin (Serva, Heidelberg, FRG); [7,8${ }^{3} \mathrm{H}$ ]dopamine (specific activity, $50 \mathrm{Ci} / \mathrm{mmol}$; Radiochemical Centre, Amersham, UK).

Animals. Cats of both sexes ( 2 to $3 \mathrm{~kg}$ ) were anesthetized with urethan-chloralose $(645 / 64.5 \mathrm{mg} / \mathrm{kg})$, and the brains were rapidly removed and dissected over a chilled plate.

Superfusion experiments. Tissue cylinders of cat neostriatum with a diameter of $3 \mathrm{~mm}$ were punched out from frontal sections, approximately between the frontal planes (14.0 to 17.0; Jasper and Ajmone-Marsan, 1960) and cut into 0.3-mm-thick disk-shaped slices (wet weight $\sim 2$ mg per slice), using a Mcllwain tissue chopper. About 25 striatal slices obtained from one cat were incubated in $6 \mathrm{ml}$ of Krebs medium, containing $0.1 \mu \mathrm{M}\left[{ }^{3} \mathrm{H}\right]$ dopamine and $500 \mu \mathrm{M}$ ascorbic acid at room temperature $\left(\sim 22^{\circ} \mathrm{C}\right)$ for $30 \mathrm{~min}$. The composition of the Krebs bicarbonate medium was (in $\mathrm{mM}$ ): $\mathrm{NaCl}, 118 ; \mathrm{KCl}, 5 ; \mathrm{CaCl}_{2}$, 2; $\mathrm{NaHCO}_{3}, 25 ; \mathrm{KH}_{2} \mathrm{PO}_{4}, 2$; $\mathrm{Na}_{2}$ EDTA, 0.02; glucose, 11.1. The buffer was saturated with oxycarbon $\left(95 \% \mathrm{O}_{2} /\right.$ $5 \% \mathrm{CO}_{2}$ ). The $\mathrm{pH}$ was 7.4. In some experiments $0.05 \%$ BSA and $0.004 \%$ bacitracin were present in the superfusion medium. After incubation, two slices each were transferred into superfusion chambers of glass, where they were held by polypropylene nets within a Plexiglas tube (diameter $4 \mathrm{~mm}$ ) between two gold electrodes $2 \mathrm{~cm}$ apart. The slices were superfused with Krebs medium at a rate of $1.2 \mathrm{ml} / \mathrm{min}$ at $30^{\circ} \mathrm{C}$. Collection of 5 -min fractions $(6 \mathrm{ml})$ began after $60 \mathrm{~min}$. The slices were stimulated by monophasic, rectangular pulses of 2 msec duration and a frequency of $2 \mathrm{~Hz}$ (current strength $12 \mathrm{~mA}$ ) twice for 2 min after $75 \mathrm{~min}\left(\mathrm{~S}_{1}\right)$ and $150 \mathrm{~min}\left(\mathrm{~S}_{2}\right)$ of superfusion.

Test substances were present between 120 and $170 \mathrm{~min}$ of superfusion. Total superfusion time was $200 \mathrm{~min}$. At the end of the experiment, tissue slices were recovered and solubilized in concentrated formic acid. Total tritium activity in the 6-ml fractions and samples with solubilized tissue slices were measured by quench corrected liquid scintillation spectrometry. The basal outflow of tritium was expressed as fractional rate per minute, which was calculated by dividing the tritium activity in each 5-min fraction by the total tritium activity present in the slices at the onset of the respective collection period. Stimulation-evoked tritium overflow was calculated by subtracting basal outflow during $2 \mathrm{~min}$ of stimulation and the following $13 \mathrm{~min}$. Basal outflow during that time period was extrapolated from the basal outflow measured in the fraction before and the fifth fraction after stimulation.

Drug effects on stimulation-evoked tritium overflow are expressed as the ratio of the overflow evoked by $\mathrm{S}_{2}$ to that evoked by $S_{1}\left(S_{2} / S_{1}\right)$. In order to quantify drug effects on basal tritium outflow, the ratios of the fractional rate of tritium overflow in the fraction immediately before $\mathrm{S}_{2}\left(b_{2}\right)$ to that in the fraction before drug addition $\left(b_{1}\right)$ were determined $\left(b_{2} / b_{1}\right)$.

\section{Results}

Basal tritium efflux from cat striatal slices previously labeled with $\left[{ }^{3} \mathrm{H}\right]$ dopamine was initially rapid but reached a constant rate of approximately $0.03 \% / \mathrm{min}$ of total tritium content after $60 \mathrm{~min}$ of superfusion. The presence of BSA and bacitracin in the superfusion medium had no influence on basal tritium efflux. Stimulation by electric pulses $(2 \mathrm{~Hz}, 2 \mathrm{msec}, 12 \mathrm{~mA})$ during 2 min markedly increased tritium efflux (Fig. 1). The tritium overflow elicited by the first stimulation period $\left(S_{1}\right)$ amounted to $0.43 \pm 0.03 \%(n=60)$ in the absence and to $0.49 \pm 0.05 \%(n=77)$ in the presence of BSA and bacitracin. The ratios of tritium overflow evoked by a second stimulation period $\left(\mathrm{S}_{2}\right)$ to that of $\mathrm{S}_{1}\left(\mathrm{~S}_{2} / \mathrm{S}_{1}\right)$ under control conditions were $0.92 \pm 0.05(n=40)$ in the absence and $0.90 \pm 0.04(n=46)$ in the presence of BSA and bacitracin.

Tetrodotoxin $(0.1 \mu \mathrm{M})$ induced a marked inhibition of basal tritium efflux and abolished the response to electric stimulation nearly completely (Fig. 1). Omission of $\mathrm{Ca}^{2+}$ in the superfusion medium also abolished the response to electric stimulation, but reduced basal tritium outflow to a lesser degree (data not shown).

Apomorphine, added 30 min before $S_{2}$, induced a concentration-dependent inhibition of electrically evoked tritium efflux. Basal tritium efflux was also inhibited, but to a lesser degree. Similar effects were seen in the absence and presence of BSA and bacitracin (Table I).

In the presence of BSA and bacitracin, CCK-8s induced a marked inhibition both of basal and electrically evoked tritium efflux in a concentration-dependent, biphasic manner (Fig. 2). The maximal inhibition both of basal and evoked tritium efflux occurred at $10^{-11} \mathrm{M}$. Significant effects were obtained in the concentration 


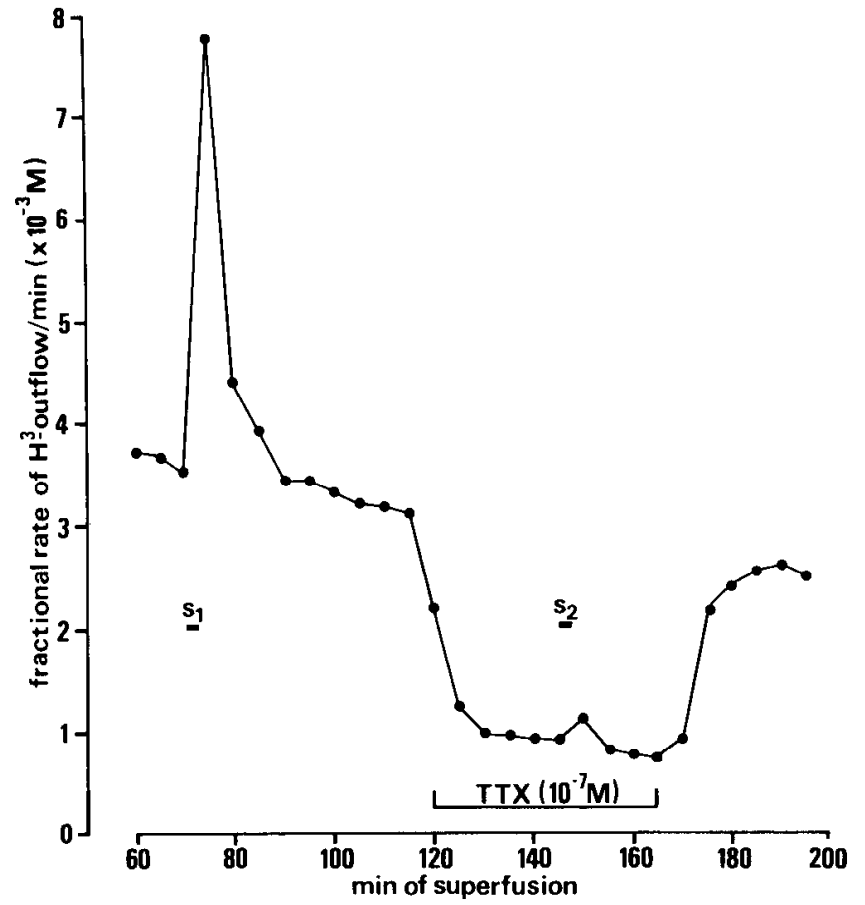

Figure 1. Effect of tetrodotoxin $(T T X)\left(10^{-7} \mathrm{M}\right)$ on basal and electrically evoked tritium outflow from slices of cat caudate nucleus previously labeled with $\left[{ }^{3} \mathrm{H}\right]$ dopamine. After preincubation with $\left[{ }^{3} \mathrm{H}\right]$ dopamine, slices were stimulated twice each at $2 \mathrm{~Hz}$ for $2 \mathrm{~min}\left(\mathrm{~S}_{1}, \mathrm{~S}_{2}\right)$. Tetrodotoxin was added as indicated. Means of four experiments. Standard errors were maximally $15 \%$ of corresponding means.

\section{TABLE I}

Effect of apomorphine on tritium outflow

Slices of cat caudate nucleus previously labled with $\left[{ }^{3} \mathrm{H}\right]$ dopamine were superfused and stimulated twice for $2 \mathrm{~min}$ each at $2 \mathrm{~Hz}\left(\mathrm{~S}_{1} / \mathrm{S}_{2}\right)$. Various concentrations of apomorphine were added $30 \mathrm{~min}$ before $\mathrm{S}_{2}$. BSA and bacitracin were either absent or continuously present throughout the experiments. Values are the ratios of the electrically evoked overflows evoked by $S_{2}$ and $S_{1}\left(S_{2} / S_{1}\right)$ and of the basal outflows immediately before $S_{2}$ and before drug addition $\left(b_{2} / b_{1}\right)$. Values are means \pm SEM of six determinations.

\begin{tabular}{ccccc}
\hline $\begin{array}{c}\text { Apomorphine } \\
(\mu \mathrm{M})\end{array}$ & \multicolumn{2}{c}{$\begin{array}{c}\mathrm{BSA}+\text { Bacitracin in the } \\
\text { Medium }\end{array}$} & \multicolumn{2}{c}{ No Additions in the Medium } \\
\cline { 2 - 5 } & $\mathrm{S}_{2} / \mathrm{S}_{1}$ & $b_{2} / b_{1}$ & $\mathrm{~S}_{2} / \mathrm{S}_{1}$ & $b_{2} / b_{1}$ \\
\hline 0 & $0.89 \pm 0.06$ & $0.74 \pm 0.01$ & $0.92 \pm 0.04$ & $0.82 \pm 0.01$ \\
0.001 & $0.75 \pm 0.07$ & $0.74 \pm 0.01$ & $0.89 \pm 0.07$ & $0.82 \pm 0.01$ \\
0.01 & $0.58 \pm 0.07^{a}$ & $0.70 \pm 0.01^{b}$ & $0.62 \pm 0.09^{b}$ & $0.75 \pm 0.01^{a}$ \\
0.1 & $0.31 \pm 0.03^{c}$ & $0.63 \pm 0.02^{a}$ & $0.33 \pm 0.04^{a}$ & $0.68 \pm 0.02^{c}$ \\
1.0 & $0.22 \pm 0.03^{c}$ & $0.63 \pm 0.02^{a}$ & $0.27 \pm 0.03^{c}$ & $0.66 \pm 0.01^{c}$ \\
\hline
\end{tabular}

${ }^{a} 2 p<0.01$ (Student's $t$ test).

${ }^{b} 2 p<0.05$ (Student's $t$ test).

c $2 p<0.001$ (Student's $t$ test).

range from $10^{-14}$ to $10^{-7} \mathrm{M}$. The non-sulfated CCK-8 had no significant effects in a concentration range from $10^{-10}$ to $10^{-7} \mathrm{M}$ (Fig. 2). In the experiments where BSA and bacitracin were present, CCK-8s induced immediately after addition to the superfusion medium a clear inhibition of basal tritium efflux, remaining on a constant level during the following $45 \mathrm{~min}$. However, after cessation of superfusion of CCK-8s, tritium efflux increased again during the following $20 \mathrm{~min}$, reaching the previous level (Fig. 3). In the presence of BSA and bacitracin, combi-

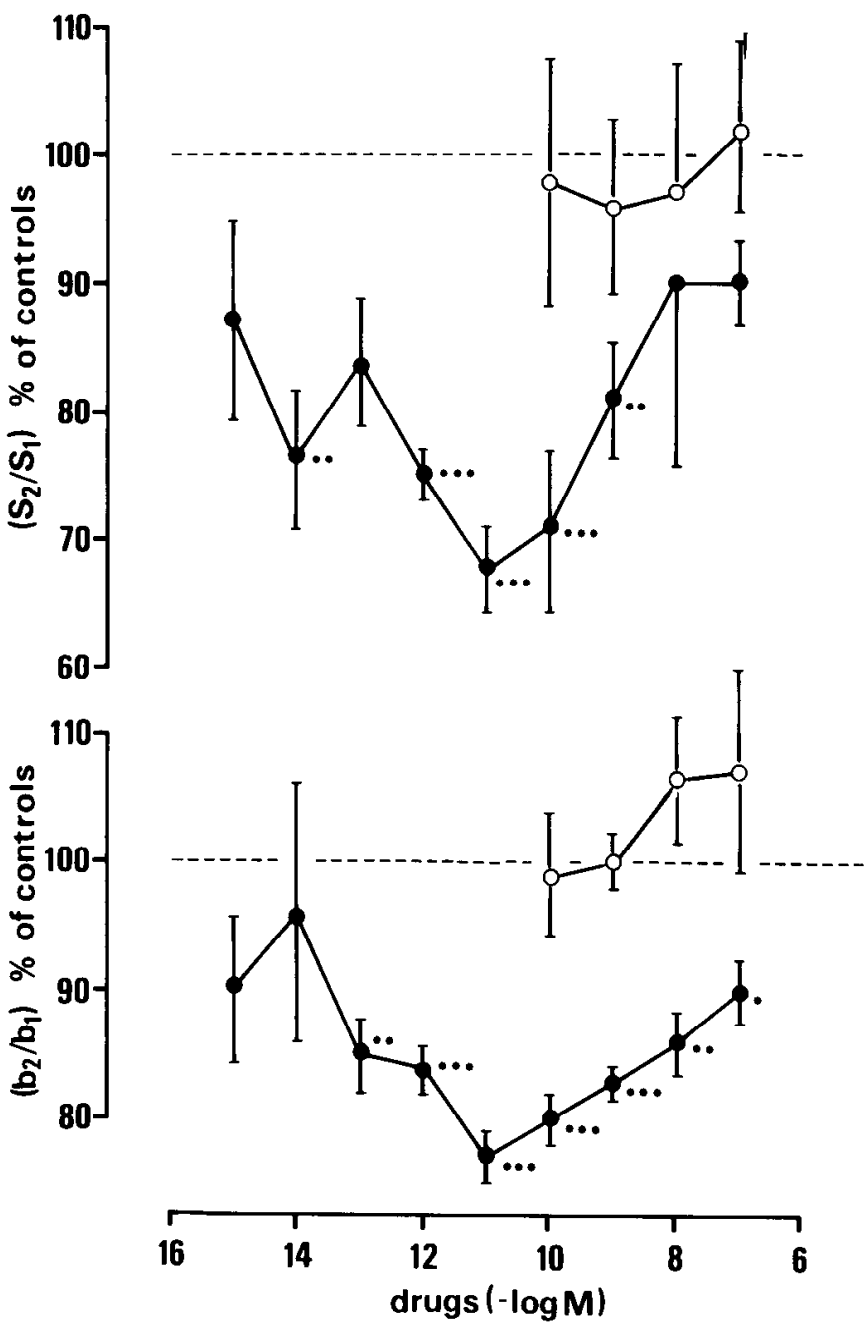

Figure 2. Effects of sulfated CCK-8 (O) and the nonsulfated form of CCK-8 (O) on basal and electrically evoked tritium outflow slices of cat caudate nucleus previously labeled with $\left[{ }^{3} \mathrm{H}\right]$ dopamine. After preincubation with $\left[{ }^{3} \mathrm{H}\right]$ dopamine, slices were superfused with Krebs medium containing BSA and bacitracin and stimulated twice each at $2 \mathrm{~Hz}$ for $2 \min \left(\mathrm{S}_{1}, \mathrm{~S}_{2}\right)$. Drugs were added $30 \mathrm{~min}$ before $\mathbf{S}_{2}$. Drug effects on basal tritium efflux are expressed as the ratio of the fractional tritium outflow of the fraction before $S_{2}$ to that before drugs were added $\left(b_{2} / b_{1}\right)$, as a percentage of controls. The effect on electrically evoked tritium overflow is expressed as the ratio of tritium overflow evoked by $S_{2}$ to that evoked by $S_{1}$ as a percentage of controls. Means \pm SEM of four to six experiments. Control values were: $\left(b_{2} / b_{1}\right)=0.80 \pm 0.01(n=16) ;\left(\mathrm{S}_{2} / \mathrm{S}_{1}\right)=0.90 \pm$ $0.05(n=16)$.

nations of CCK-8s $\left(10^{-12} \mathrm{M}\right)$ with $10^{-9} \mathrm{M}$ but not with $10^{-7} \mathrm{M}$ apomorphine gave additive effects (Table II).

In medium without BSA and bacitracin, CCK-8s, added $30 \mathrm{~min}$ before $\mathrm{S}_{2}$, enhanced both basal and electrically evoked tritium efflux from slices of cat caudate nucleus with a significant effect occurring at $10^{-7} \mathrm{M}$ (Fig. 4). The non-sulfated form had no significant effect in the same concentration range (Fig. 4).

\section{Discussion}

Electrically evoked tritium outflow from slices of cat caudate nucleus preincubated with low concentrations of 


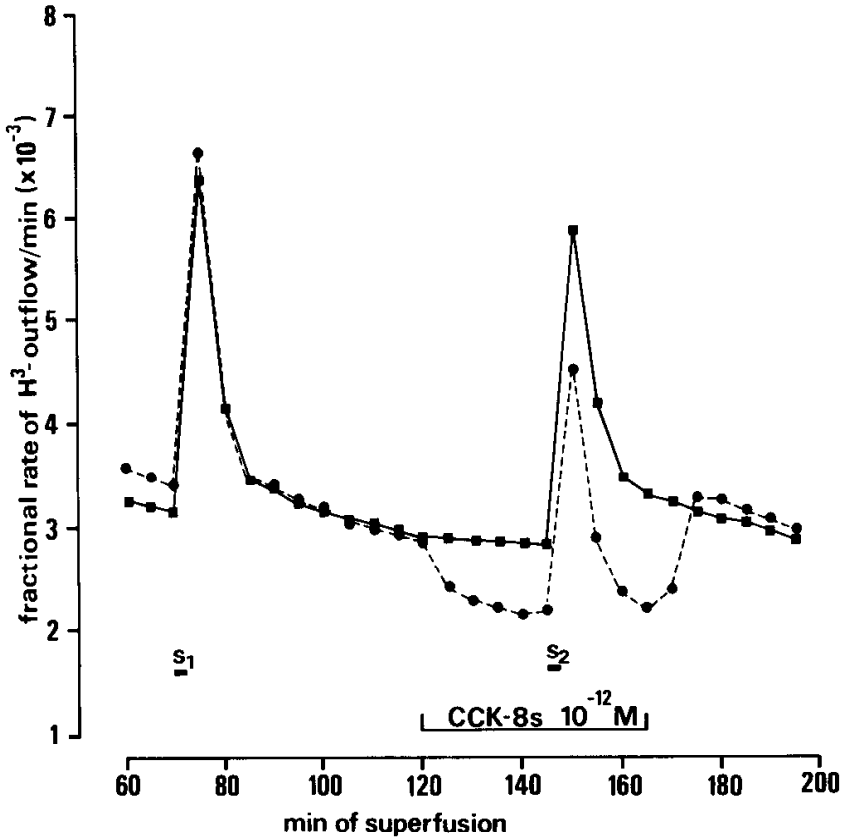

Figure 3. Outflow of tritium from slices of cat caudate nucleus preincubated with $\left[{ }^{3} \mathrm{H}\right]$ dopamine and superfused with Krebs medium containing BSA and bacitracin. Slices were stimulated twice for $2 \mathrm{~min}$ each at $2 \mathrm{~Hz}\left(\mathrm{~S}_{1}, \mathrm{~S}_{2}\right)$. In the experiments represented by solid circles, CCK-8 $\left(10^{-12} \mathrm{M}\right)$ was added as indicated. Means of four experiments. Standard errors were maximally $15 \%$ of corresponding means.

TABLE II

Effect of combinations of CCK-8s and apomorphine on evoked tritium outflow

Slices of cat caudate nucleus previously labeled with $\left[{ }^{3} \mathrm{H}\right]$ dopamine were superfused with Krebs medium containing $0.5 \%$ BSA and $0.04 \%$ bacitracin and were stimulated twice for 2 min each at $2 \mathrm{~Hz}\left(\mathrm{~S}_{1} / \mathrm{S}_{2}\right)$. Apomorphine and CCK-8s were added alone or in combination $30 \mathrm{~min}$ before $S_{2}$. Values are the ratios of the electrically evoked overflows evoked by $S_{2}$ and $S_{1}\left(S_{2} / S_{1}\right)$. Values are means \pm SEM of the numbers of experiments indicated.

\begin{tabular}{lcc}
\hline \multicolumn{1}{c}{ Drugs } & $S_{2} / S_{1}$ & No. of Experiments \\
\hline None & $0.87 \pm 0.03$ & 12 \\
Apomorphine $\left(10^{-9} \mathrm{M}\right)$ & $0.73 \pm 0.04$ & 10 \\
Apomorphine $\left(10^{-7} \mathrm{M}\right)$ & $0.31 \pm 0.03$ & 8 \\
CCK-8s $\left(10^{-12} \mathrm{M}\right)$ & $0.69 \pm 0.03$ & 6 \\
Apomorphine $\left(10^{-9} \mathrm{M}\right)$ & $0.58 \pm 0.08$ & 4 \\
$\quad+$ CCK-8s $\left(10^{-12} \mathrm{M}\right)$ & & \\
Apomorphine $\left(10^{-7} \mathrm{M}\right)$ & $0.31 \pm 0.02$ & 4 \\
$\quad+$ CCK-8s $\left(10^{-12} \mathrm{M}\right)$ & & \\
\hline
\end{tabular}

$\left[{ }^{3} \mathrm{H}\right]$ dopamine was abolished by tetrodotoxin or by calcium-free medium, indicating that it reflects action potential-evoked $\left[{ }^{3} \mathrm{H}\right]$ dopamine release. Furthermore, the observation that tetrodotoxin or omission of calcium from the superfusion medium also depressed basal tritium outflow suggests that, under the described experimental conditions, action potentials occur in dopaminergic fibers in slices of cat caudate nucleus, either spontaneously or generated by an endogenous factor. Apomorphine depressed electrically evoked tritium outflow from slices of cat caudate nucleus, indicating that in the cat caudate nucleus, similar to other species,
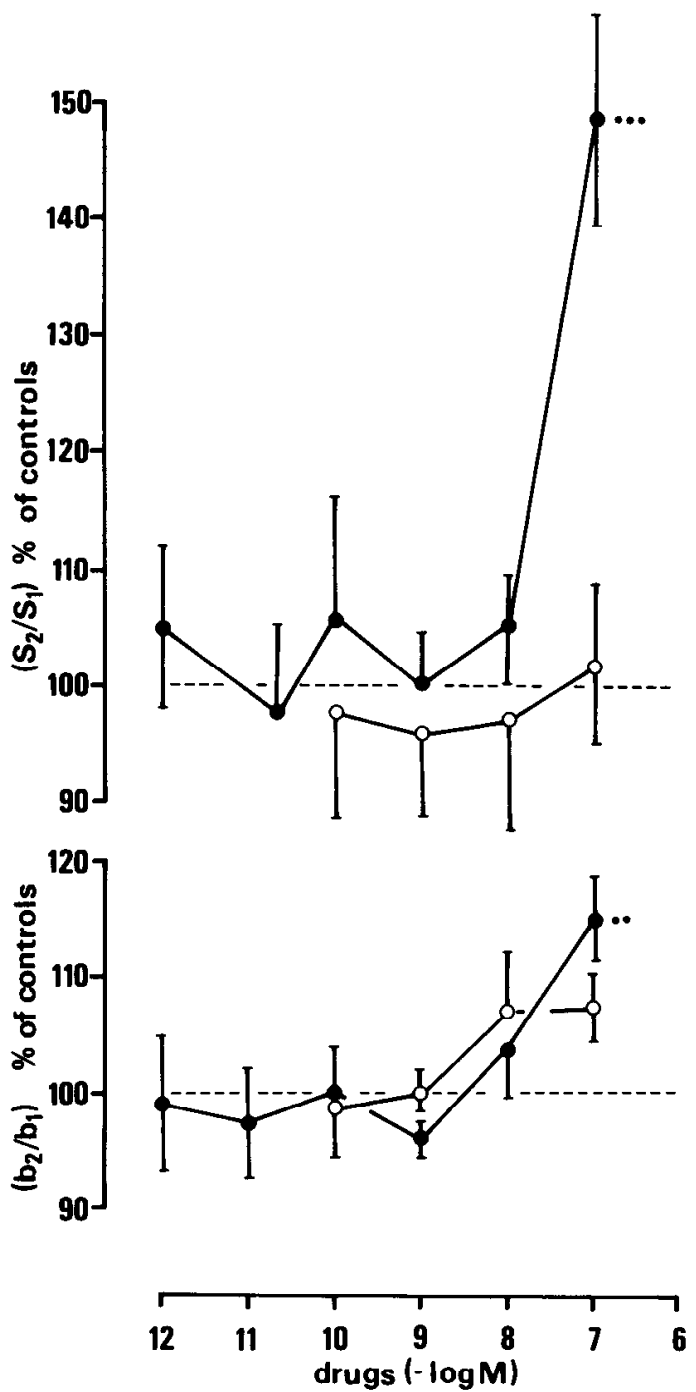

Figure 4. Effects of sulfated CCK-8 (๑) and the non-sulfated form of CCK-8 $(\mathrm{O})$ on basal and electrically evoked tritium outflow from slices of cat caudate nucleus previously labeled with $\left[{ }^{3} \mathrm{H}\right]$ dopamine. After preincubation with $\left[{ }^{3} \mathrm{H}\right]$ dopamine, slices were superfused with Krebs medium and stimulated twice each at $2 \mathrm{~Hz}$ for $2 \mathrm{~min}\left(\mathrm{~S}_{1}, \mathrm{~S}_{2}\right)$. Drugs were added $30 \mathrm{~min}$ before $\mathrm{S}_{2}$. Drug effects on basal tritium efflux are expressed as the ratio of the fractional tritium outflow of the fraction before $S_{2}$ to that before drugs were added $\left(b_{2} / b_{1}\right)$ as a percentage of controls. The effect on electrically evoked tritium is expressed as the ratio of tritium overflow evoked by $S_{2}$ to that evoked by $S_{1}$ as a percentage of controls. Means \pm S.E.M. of three to four experiments. Control values were: $\left(b_{2} / b_{1}\right)=0.81 \pm 0.02(n=$ $22) ;\left(\mathrm{S}_{2} / \mathrm{S}_{1}\right)=0.82 \pm 0.035(n=22)$. Significant differences from controls: $* * *, 2 p<0.001 ; * *, 2 p<0.01 ; *, 2 p<0.05$ (Student's $t$ test).

presynaptic inhibitory dopamine autoreceptors are present (Westfall et al., 1976; Starke et al., 1978).

The present findings demonstrate that very low concentrations of CCK $-8 \mathrm{~s}$, but not the unsulfated form of the peptide, inhibit both basal and electrically evoked tritium efflux from slices of cat caudate nucleus. CCK$8 \mathrm{~s}$ was efficient in causing this effect in concentrations down to $10^{-14} \mathrm{M}$, and the maximum effect was obtained with $10^{-11} \mathrm{M}$. However, these effects were only observed when BSA and bacitracin were present in the superfusion 
medium. In contrast, without these additions, no inhibitory effects of CCK-8s could be observed, but instead a marked enhancement, both of of evoked and basal tritium outflow, was seen. The specificity of these effects was demonstrated by the fact that the unsulfated form of CCK-8 caused neither inhibition nor facilitation of tritium efflux. Also, in other investigations the unsulfated form of CCK-8 was found to lack biological activity. For instance, in the rat pancreas (Robbebrecht et al., 1978) and also in electrophysiological studies in the central nervous system (Dodd and Kelly, 1979; Skirboll et al., 1981), the non-sulfated form of CCK-8 was inactive.

The reason for the different effects of CCK-8s seen in the two types of incubation medium is at present unclear. Addition of BSA and bacitracin to the medium had no detectable influence either on basal and evoked tritium outflow in control experiments or on the inhibitory effect of apomorphine. This suggests that BSA and bacitracin specifically interfere with the effect of CCK-8s on dopamine release. It may be speculated that, in the absence of BSA and bacitracin, CCK-8s is broken down and that metabolites act on a different type of CCK receptor resulting in an enhancement of dopamine release.

As pointed out by Thorack et al. (1965), every tissue component reacts in its own specific way upon incubation conditions. In rat striatal slices, electron microscopic analysis has disclosed a marked swelling and destruction of glial tissue and a pronounced increase in extracellular space (Hökfelt, 1968). Destruction of glial components and increase in extracellular space was found to be prevented by addition of macromolecules such as dextran T70 to the medium (Hökfelt, 1970). It may therefore be speculated that the inhibitory effect of CCK-8s on dopamine release seen at low concentrations requires an intact glial environment and that destruction of glial elements provides an experimental situation where different reactions are seen. Since CCK-like peptides occur in brain in much lower concentrations than do classical transmitters such as dopamine, the inhibitory effect of CCK-8s on dopamine release seen at low concentrations in the presence of BSA and bacitracin may be of greater physiological significance than the opposite effect seen at higher concentrations and in the absence of BSA and bacitracin. In contrast, the effect of apomorphine on dopamine release is unaffected by BSA and bacitracin.

The release of dopamine from nerve terminals present in striatal tissue of many species has been shown to be subject to a local feedback inhibition mediated by presynaptic dopamine autoreceptors (Westfall et al., 1976; Starke et al., 1978). The present findings indicate that CCK-like peptides also may be important for regulating action potential-evoked dopamine release. There are several possible mechanisms by which CCK-8s could influence action potential-evoked dopamine release. For instance, it could inhibit dopamine release directly by interacting with presynaptic CCK-specific autoreceptors being independent from dopamine autoreceptors, or it could simply modulate the sensitivity of presynaptic dopamine autoreceptors. Another possibility is that CCK-8s mobilizes an endogenous factor which in turn inhibits dopamine release.

Based on the present findings that the effects of $\mathrm{CCK}$ -
$8 \mathrm{~s}$ and apomorphine were not additive when concentrations giving near-maximal inhibition were combined, it appears unlikely that both compounds influence dopamine release by completely independent mechanisms.

The observation that combination of $10^{-12} \mathrm{M}$ CCK-8s with a threshold concentration of apomorphine $\left(10^{-9} \mathrm{M}\right)$ instead produced an additive effect suggests that CCK$8 \mathrm{~s}$ and apomorphine have a common site of action and that CCK-8s possibly modulates the sensitivity of presynaptic dopamine autoreceptors. However, other mechanisms such as mediation by endogenous factors or effects on membrane conductance cannot be excluded. The clarification of this problem requires further investigations.

In conclusion, based on the present findings, it is suggested that, in dopamine/CCK coexistence regions, CCK-8s is involved in regulating dopamine release.

Intraventricular administration of CCK-8s has been reported to increase dopamine turnover in the rat striatum (Fekete et al., 1981), whereas Fuxe et al. (1981) found a decrease in certain areas of the caudate nucleus and nucleus accumbens of the rat. These opposing effects of CCK-8s on dopamine turnover illustrate again that the interaction of CCK-like peptides with dopaminergic systems is complex and possibly strongly dependent upon experimental conditions. The situation appears even more complex in the light of recent findings that CCK$8 \mathrm{~s}$ release in rat neostriatum in turn is modulated by dopamine (Meyer and Krauss, 1983).

The inhibitory effect of CCK-8s on dopamine release shown in the present study occurred at remarkably low concentrations. In spite of the fact that peptides in general are not assumed to cross the blood-brain barrier, it may be speculated that such small amounts of peptide may in fact enter the brain from the bloodstream and cause a biological effect.

These findings are also of interest in relation to recent published data indicating that intravenous injection of CCK and/or coeruletide causes beneficial effects in patients with schizophrenia (Moroji et al., 1982; Nair et al., 1982, 1983). Since schizophrenia has been associated with overactivity of dopamine neurons, an inhibitory effect of CCK on dopamine release would be in agreement with the beneficial effect of CCK in this disease.

It could therefore be important to elucidate whether CCK exerts inhibitory effects on dopamine release also in the human brain.

\section{References}

Agnati, L., K. Fuxe, F. Benfenati, M. F. Celani, N. Battistini, V. Mutt, L. Cariccioli, G. Galli, and T. Hökfelt (1983) Differential modulation by CCK- 8 and CCK- 4 of $\left[{ }^{3} \mathrm{H}\right]$ spiperone binding sites linked to dopamine and 5-hydroxytryptamine receptors in the brain of the rat. Neurosci. Lett. 35: 179-183.

Beinfeld, M. C. (1981) An HPLC and RIA analysis of the cholecystokinin peptides in rat brain. Neuropeptides 7: 203209.

Beinfeld, M. C., D. K. Meyer, R. L. Eskay, R. T. Jensen, and M. J. Brownstein (1981) The distribution of cholecystokinin immunoreactivity in the central nervous system of the rat as determined by radioimmunoassay. Brain Res. 212: 51-57.

Dahlström, A., and K. Fuxe (1964) Evidence for the existence of monoamine-containing neurons in the central nervous system. I. Demonstration of monoamines in the cell bodies 
of brain stem neurons. Acta Physiol. Scand. 62 (Suppl. 232): $1-55$.

Dockray, G. J. (1976) Immunochemical evidence of cholecystokinin-like peptides in brain. Nature 264: 568-570.

Dockray, G. J. (1980) Cholecystokinins in rat cerebral cortex: Identification, purification and characterization by immunochemical methods. Brain Res. 188: 155-165.

Dockray, G. J., R. A. Gregory, J. B. Hutchinson, J. J. Harris, and M. J. Runswick (1978) Isolation, structure and biological activity of two cholecystokinin octapeptides from sheep brain. Nature 274: 711-713.

Dodd, J., and J. S. Kelly (1979) Excitation of CA1 pyramidal neurones of the hippocampus by the tetra- and octa-peptide C-terminal fragments of cholecystokinin. J. Physiol. (Lond.) 295: 61-62.

Fekete, M., T. Kadar, B. Penke, K. Kovacs, and G. Telegdy (1981) Influence of cholecystokinin octapeptide sulfate ester on monoamine metabolism in rats. J. Neural. Transm. 50: 81-88.

Fuxe, K., K. Andersson, V. Locatelli, L. Agnati, T. Hökfelt, L. Skirboll, and V. Mutt (1980) Cholecystokinin in peptides produce marked reduction of dopamine turnover in discrete areas in the rat brain following intraventricular injection. Eur. J. Pharmacol. 67: 329-331.

Fuxe, K., L. F. Agnati, F. Benfenati, M. Cimmino, S. Algeri, T. Hökfelt, and V. Mutt (1981) Modulation by cholecystokinins of ${ }^{3} \mathrm{H}$-spiroperidol binding in rat striatum: Evidence for increased affinity and reduction in the number of binding sites. Acta Physiol. Scand. 113: 567-569.

Hökfelt, T. (1968) In vitro studies on central and peripheral monoamine neurons at the ultrastructural level. Z. Zellforsch. 91: 1-74.

Hökfelt, T. (1970) Electron microscopic studies on peripheral and central monoamine neurons. In Aspects of Neuroendocrinology, W. Bargmann and B. Scharrer, eds., pp. 79-94, Springer-Verlag, Berlin.

Hökfelt, T., J. F. Rehfeld, L. R. Skirboll, B. Ivemark, M. Goldstein, and K. Markey (1980a) Evidence for coexistence of dopamine and CCK in mesolimbic neurons. Nature 285: 476-478.

Hökfelt, T., L. Skirboll, J. F. Rehfeld, M. Goldstein, K. Markey, and O. Dann (1980b) A subpopulation of mesencephalic dopamine neurons projecting to limbic areas contains a cholecystokinin-like peptide: Evidence from immunohistochemistry combined with retrograde tracing. Neuroscience 5: 2093-2124.

Hökfelt, T., J. M. Lundberg, L. Skirboll, O. Johansson, M. Schultzberg, and S. R. Vincent (1982) Coexistence of classical transmitters and peptides in neurons. In Co-transmission, A. C. Cuello, ed., pp. 77-126, MacMillan, London.

Ivy, A. C., and E. Oldberg (1928) Hormone activation mechanism for gall bladder contraction. Am. J. Physiol. 85: 381383 .
Jasper, H. H., and C. Ajmone-Marsan (1960) A Stereotaxic Atlas of the Diencephalon of the Cat. University of Toronto Press, Toronto.

Jorpes, J. K., and V. Mutt (1973) Secretion and cholecystokinin (CCK). In Handbook of Experimental Pharmacology, J. E. Jorpes and V. Mutt, eds., Vol. 34, pp. 1-179, Springer-Verlag, Berlin.

Kovacs, G. A., G. Szabo, B. Penke, and G. Telegdy (1981) Effects of cholecystokinin on striatal dopamine metabolism and on apomorphine-induced stereotyped cage climbing in mouse. Eur. J. Pharmacol. 69: 313-319.

Meyer, D. K., and J. Krauss (1983) Dopamine modulates cholecystokinin release in neostriatum. Nature $301: 338-340$.

Meyer, D. K., M. C. Beinfeld, W. H. Oertel, and M. J. Brownstein (1982) Origin of the cholecystokinin-containing fibers in the rat caudatoputamen. Science 215: 187-188.

Moroji, T., N. Watanabe, N. Aoki, and S. Ito (1982) Antipsychotic effects of ceruletide (coerulein) on chronic schizophrenia. Arch. Gen. Psychiatry 39: 485-486.

Nair, N. P. V., D. M. Bloom, and J. N. Nestoros (1982) Cholecystokinin appears to have antipsychotic properties. Prog. Neuropsychopharmacol. Biol. Psychiatry 6: 509-512.

Nair, N. P. V., D. M. Bloom, J. N. Nestoros, and G. Schwarz (1983) Therapeutic efficacy of cholecystokinin in neuroleptic-resistant schizophrenic subjects. Psychopharmacol. Bull. 19: $134-136$.

Rehfeld, J. F. (1977) Cholecystokinins and gastrins in the brain and gut. Acta Pharmacol. Toxicol. 41 (Suppl. 4): 24.

Robberbrecht, P., S. Deschodt-Lanckman, and J. J. Vanderhaeghen (1978) Demonstration of biological activity of brain gastrin-like peptidic material in the human: Its relationship with the COOH-terminal octapeptide of cholecystokinin. Proc. Natl. Acad. Sci. U. S. A. 75: 524-528.

Skirboll, L., A. A. Grace, D. W. Hommer, J. Rehfeld, M. Goldstein, T. Hökfelt, and S. Bunney (1981) Peptide monoamine coexistence: Studies of the actions of a cholecystokinin-like peptide on the electrical activity of midbrain dopamine neurons. Neuroscience 6: 2111-2124.

Starke, K., W. Reimann, A. Zumstein, and G. Hertting (1978) Effect of dopamine receptor agonists and antagonists on release of dopamine in the receptor in the rabbit caudate nucleus in vitro. Naunyn-Schmiedebergs Arch. Pharmacol. 305: 27-36.

Thorack, R. M., M. L. Duffy, and J. M. Haynes (1965) The effect of anisotonic media upon cellular ultrastructure in fresh and fixed rat brain. Z. Zellforsch. 66: 690-700.

Vanderhaeghen, J. J., J. C. Signeau, and W. Gepts (1975) New peptide in the vertebrate CNS reacting with gastrin antibodies. Nature (Lond.) 257: 604-605.

Westfall, T. C., M. J. Benson, M. f. Giorguieff, and J. Glowinski (1976) The role of presynaptic receptors in the release and synthesis of ${ }^{3} \mathrm{H}$-dopamine by slices of rat striatum. NaunynSchmiedebergs Arch. Pharmacol. 292: 279-287. 